\title{
Blood Serum Stability Limit and Maximum Storage Time of Bovine Samples
}

\author{
Danijel Kovačević1, Marko Cincović', Branislava Belić', Radojica Đoković \& Mira Majkić1
}

\begin{abstract}
Background: Measuring metabolic parameters in the blood has been an indispensable tool for assessing the productive and health status of dairy cows for more than 100 years. The values of laboratory parameters depend on various preanalytical, analytical and postanalytical factors. The most important preanalytical factors are sample transport time and temperature, hemolysis, anticoagulant type, and sample volume. Preanalytical factors can lead to reduced stability of the analyte in the sample, which changes their concentration. Loss of stability changes the time of storage and manipulation of the sample, which determines the criteria for its acceptance or rejection. The two stability indicators are stability limit and maximum permissible instability. A stability limit (SL) is defined as the period of time in which a property variation does not exceed a maximum permissible instability (MPI). The aim of this study was to determine the SL and MPI for each analyte in the blood serum of cows and to determine whether SL differs in the function of the presence of preanalytical errors in the blood sample.

Materials, Methods \& Results: Three hundred samples of dairy cow origin in different periods of lactation participated in this research. They were classified into 6 groups of 50 samples: according to the time from sampling to processing in the laboratory (0-4 h, 4-8 h and over $8 \mathrm{~h}$; all transported on dry ice, protected from environmental factors, without preanalytical errors) and according to the presence of preanalytical errors (group with hemolysis, a group transported at ambient temperature and a group with a small sample volume). Each sample was aliquoted in two portions. One portion was left at $+4^{\circ} \mathrm{C}$ and tested once a day for 6 days of sample storage, and the second portion, placed at $-20^{\circ} \mathrm{C}$, was tested once a month for 6 months. The MPI had a value ranging from 1.51 to 8.4. Metabolic profile analytes with lower MPI values (1.51-3.22) were albumin (ALB), total protein (TPROT), UREA, glucose (GLU), calcium (Ca), and phosphorus (P). Higher MPI values (5.1-8.4) were found for nonesterified fatty acids (NEFA), beta-hydroxybutirate (BHB), cholesterol (CHOL), triglycerides (TGC), total bilirubin (TBIL) and aspartat aminotransferase (AST). For most parameters, we can conclude that their PD\% changed faster in storage conditions at $+4^{\circ} \mathrm{C}$ compared to the regime of $-20^{\circ} \mathrm{C}$. The largest number of biochemical analytes in bovine blood serum shows preserved stability in the first 6 days at $+4^{\circ} \mathrm{C}$ or 6 months at $-20^{\circ} \mathrm{C}$ if transported to the laboratory within $8 \mathrm{~h}$ after sampling in ideal conditions and without the action of preanalytical errors. Prolonged transport under ideal conditions or the existence of preanalytical errors such as transport at room temperature, hemolysis or small sample volume shorten the stability of the ALB, NEFA, GLU, UREA and P. Concentration of all analytes decreases during the stability test except for UREA, NEFA, BHB and for CHOL and TGC in some groups. Variations in parameters such as BHB, NEFA, TBIL, AST, and Ca have shown potential clinical significance. At storage conditions at $+4^{\circ} \mathrm{C}$, clinically significant variations at at least one measurement point were found for AST (7.5\% of samples), BHB (6.1\% of samples), NEFA (9.9\% of samples) and for TBIL (in 7\% of samples).

Discussion: This study can help define acceptable delay times and storage conditions for bovine blood samples, which is of great importance because in working with farm animals it is often not possible to take samples in a short time and deliver them to the laboratory, and samples are often burdened with certain preanalytical errors with limited possibilities of re-sampling.
\end{abstract}

Keywords: bovine, blood, analytes, stability, storage, metabolic profile. 


\section{INTRODUCTION}

Measuring metabolic parameters in the blood has been an indispensable tool for assessing the productive and health status of dairy cows for more than 100 years [31]. Determining metabolic parameters has contributed to the understanding of the physiology of the peripartum period, knowledge of homeoresis, metabolic stress, as well as the diagnosis of many diseases [12,21,32].

The values of laboratory parameters depend on various preanalytical, analytical and postanalytical factors. The influence of preanalytical factors on the variation of metabolic parameters in different animal species and humans is well known, and recommendations are given for reducing preanalytical error and equalizing preanalytical activities for farm animals [18].

Preanalytical factors can lead to reduced stability of the analyte in the sample, which changes their concentration. According to Gómez-Rioja et al. [16], the stability of a biochemical analyte is defined as the capability of a sample / specimen material to retain its properties over time. Loss of stability changes the time of storage and manipulation of the sample, which determines the criteria for its acceptance or rejection [40]. The 2 stability indicators are stability limit and maximum permissible instability. A stability limit (SL) is defined as the period of time in which a property variation does not exceed a maximum permissible instability (MPI). The aim of this study was to determine the SL and MPI for each analyte in the blood serum of cows and to determine whether SL differs in the function of the presence of preanalytical errors in the blood sample.

\section{MATERIALS AND METHODS}

\section{Sampling and grouping of samples}

Three hundred samples of dairy cow origin in different periods of lactation participated in this research. They were classified into 6 groups of 50 samples: according to the time from sampling to processing in the laboratory $(0-4 \mathrm{~h}, 4-8 \mathrm{~h}$ and over $8 \mathrm{~h}$; all transported on dry ice, protected from environmental factors, without preanalytical errors) and according to the presence of preanalytical errors (group with hemolysis, a group transported at ambient temperature and a group with a small sample volume). Blood samples were collected by puncture of v.coccigea in appropriate tubes with clot activator ${ }^{1}$. After centrifugation, the amount of serum was 5-6 mL, except in small volume samples that ranged around 2-3 mL. Biochemical parameters (ALB, TPROT, UREA, GLU, NEFA, BHB, CHOL, TGC, TBIL, AST, Ca and P) were measured by standard reagents ${ }^{2}$ at automatic spectrophotometer ${ }^{3}$.

\section{Stability test model}

Each sample was aliquoted in 2 portions. One portion was left at $+4^{\circ} \mathrm{C}$ and tested once a day for 6 days of sample storage, and the second portion, placed at $-20^{\circ} \mathrm{C}$, was tested once a month for 6 months.

Gómez-Rioja et al. [16] in their protocol precisely defined the technical procedures for measuring stability: "The loss of stability is assessed by comparing measurement values of 2 samples obtained from the same patient and analyzed at different time points - basal time / sample and test time / sample. Differences are expressed using percentage deviation ( $\mathrm{PD} \%)$. $\mathrm{PD} \%$ is the difference between measured concentrations in optimal conditions (baseline sample; t0, average of replicate measurements) and its concentrations when stored for the maximum permissible storage time (test sample; $t x$ average of replicate measurements). The difference is converted into a $\%$ PD from the baseline value: PD $\%=$ $(\mathrm{tx}-\mathrm{t} 0) / \mathrm{t} 0) \times 100$. The MPI was calculated MPI $=0.5$ $\times(\mathrm{CVa}+\mathrm{CVi}) . \mathrm{A}$ PD\% $<$ MPI for all study subjects indicates that there was not a significant loss of stability within the storage time studied. A PD $\% \geq$ MPI in some of the subjects indicates that there was a significant loss of stability within the storage time studied."

\section{Statistical analysis}

Intensity of change in the value of $\mathrm{PD} \%$ per time unit was determined by calculation of linear regression parameter $b$, and regression lines were presented in figures. The potential clinical significance of changes in analyte values will be determined by comparing $\mathrm{PD} \%$ and RCV values. Potential clinical significance exists if $\mathrm{PD} \%>\mathrm{RCV}$ exists, deviation of values may be clinically significant. The analytical variation, biological variation and RCV were derived from Kovačević et al. [23]. Statistical software ${ }^{4}$ SPSS (USA) were used for analysis and results representation.

\section{RESULTS}

The MPI had a value ranging from 1.51 to 8.4. Metabolic profile analytes with lower MPI values (1.513.22) were ALB, TPROT, UREA, GLU, Ca, and P. Higher MPI values (5.1-8.4) were found for NEFA, BHB, CHOL, TGC, TBIL, AST. The results are shown in Figure 1. 
The stability of the analyte from the metabolic profile in cows is shown in Table 1 and Figures 2 and 3. The table shows the measured value of metabolites in the confidence interval of $95 \%(95 \% \mathrm{CI})$. The table shows the value of the linear regression parameter $b$, which indicates the intensity of the change in the value of PD\% per unit time (Linear b PD\%). The more stable the samples, the lower the value of this parameter. For most parameters, we can conclude that their PD\% changed faster in storage conditions at $+4^{\circ} \mathrm{C}$ compared to the regime of $-20^{\circ} \mathrm{C}$, but the change in concentration goes in the same direction (compare the linear b parameter). Concentration of all analites decrease during stability test except for UREA, NEFA, BHB and for samples CHOL and TGC in some groups.

ALB was stable for 6 days at $+4^{\circ} \mathrm{C}$ and 6 months at $-20^{\circ} \mathrm{C}$, regardless of the length of transport to the laboratory, unless the presence of negative preanalytical factors was found in the samples. If the sample was haemologized, small in volume or transported at ambient temperatures until processing in the laboratory, the ALB was stable for 4 or 5 days at $+4^{\circ} \mathrm{C}$, or for 5 months at $-20^{\circ} \mathrm{C}$. TPROTs were stable in the sample over the test period at both temperature regimes. UREA is stable for up to 6 days if adequately transported, while prolonged transport (4-8 h) and hemolysis of the sample reduce the stability of urea, which was stable for 4 days at $+4^{\circ} \mathrm{C}$. Stability after freezing was shortened to 5 months if there was a preanalytical problem such as small sample volume or transport at ambient temperature to the laboratory. Unlike ALB and TPROT whose values declined over time, the value of UREA increased during the stability test.

The stability of GLU was reduced in all cases, except when there was a short transport to the laboratory in ideal conditions. GLU was stable in the refrigerator $\left(+4^{\circ} \mathrm{C}\right)$ for 4 days with prolonged transport, 3 days with hemolysis or reduced sample volume, and 2 days if transported to the laboratory at ambient temperature. GLU during freezing $\left(-20^{\circ} \mathrm{C}\right)$ was stable for 4 to 5 months depending on the group of samples. Glucose levels decreased over time.

NEFA was stable only in the case of fast transport. With prolonged transport, NEFA was stable at $+4^{\circ} \mathrm{C}$ for 4 or 3 days, in the case of hemolysis for 3 days, and for 2 days in the case of a small-volume sample and in the case when the sample was transported to the laboratory at ambient temperature. This analyte was stable for 6 months at $-20^{\circ} \mathrm{C}$. The value of NEFA has grown over time. BHB was stable for 6 days at $+4^{\circ} \mathrm{C}$ and 6 months at $-20^{\circ} \mathrm{C}$, respectively. The value of $\mathrm{BHB}$ has grown over time.

CHOL was stable for 6 days at $+4^{\circ} \mathrm{C}$, and under freezer storage conditions $\left(-20^{\circ} \mathrm{C}\right)$ it was stable for 5 months regardless of preanalytical factors. TGC was stable for 6 days at $+4^{\circ} \mathrm{C}$, and under freezer storage conditions $\left(-20^{\circ} \mathrm{C}\right)$ it was stable for 4 months regardless of preanalytical factors. Depending on the group, CHOL and TGC values increased or decreased during the stability test. During storage in the freezer, there was an increase in CHOL in the first months, and then there was a decrease in samples that were transported for a long time, which were transported at ambient temperature and which were hemolyzed.

TBIL was stable at all test times at both temperature regimes. However, if there was hemolysis in the sample, TBIL was stable for up to 5 months at $-20^{\circ} \mathrm{C}$. AST was stable for 6 days at $+4^{\circ} \mathrm{C}$, but prolonged storage at $-20^{\circ} \mathrm{C}$ reduced the stability of this analyte, so it was stable for 5 months. The AST value decreased over time.

Ca was stable for 6 days at $+4^{\circ} \mathrm{C}$ and 6 months at $-20^{\circ} \mathrm{C}$, respectively. Stability $\mathrm{P}$ was unresolved within 4 or 5 days, or within 2 days if there was prolonged transport or hemolysis of the sample.

Variations in parameters such as BHB, NEFA, TBIL, AST, and Ca have shown potential clinical significance. At storage conditions at $+4^{\circ} \mathrm{C}$, clinically significant variations at at least one measurement point were found for AST (7.5\% of samples), BHB (6.1\% of samples), NEFA (9.9\% of samples) and for TBIL (in $7 \%$ of samples). When assessing the stability at a temperature of $-20^{\circ} \mathrm{C}$ from 0 to $1.3 \%$ of the samples shows variations that have potential clinical significance for these four analytes (Figure 4).

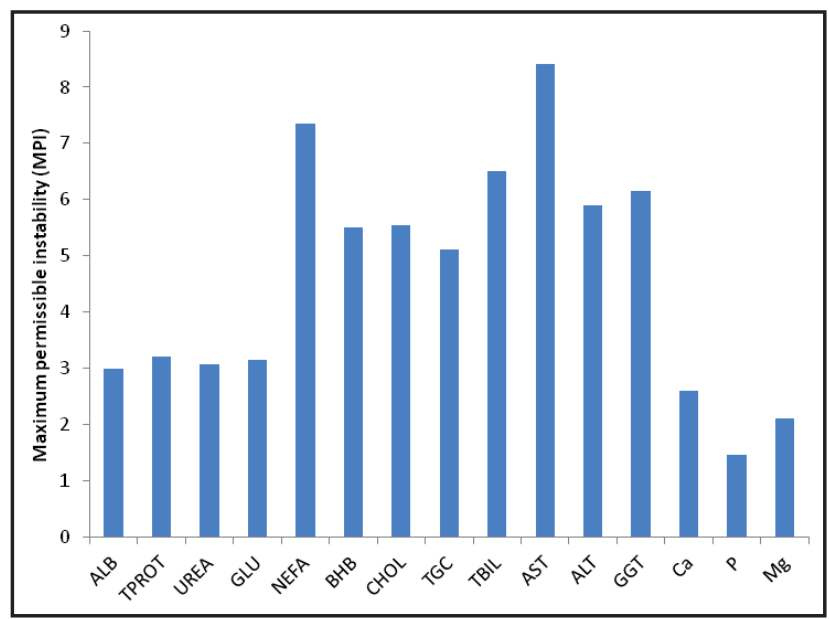

Figure 1. Maximum permissible instability (MPI) for blood serum analytes in cows. 
D. Kovačević, M. Cincović, B. Belić, R. Đoković \& M. Majkić. 2021. Blood Serum Stability Limit and Maximum Storage

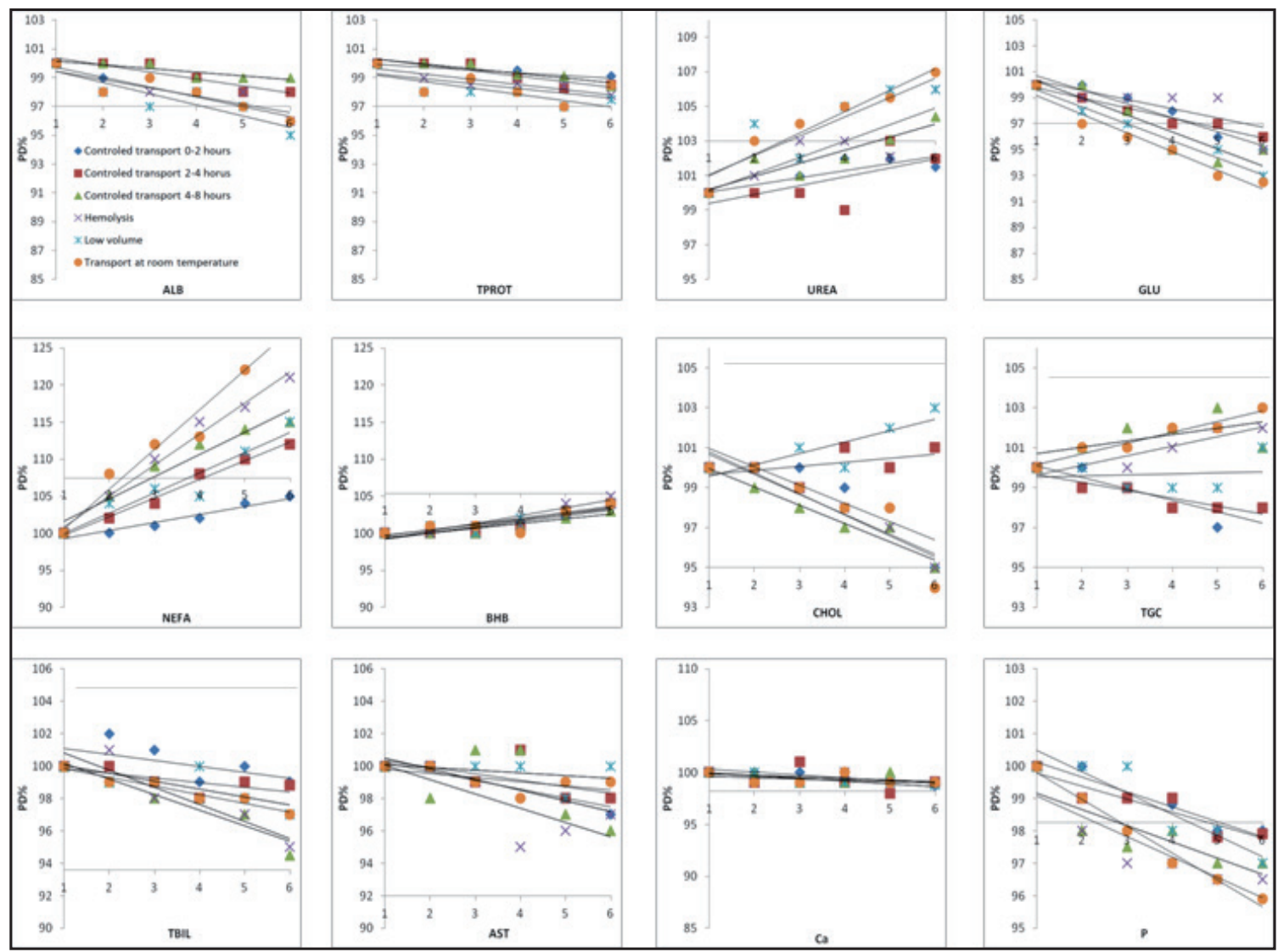

Figure 2. Blood serum analyte stability at $+4^{\circ} \mathrm{C}$ (abscissa represents 1-6 day of measurement).

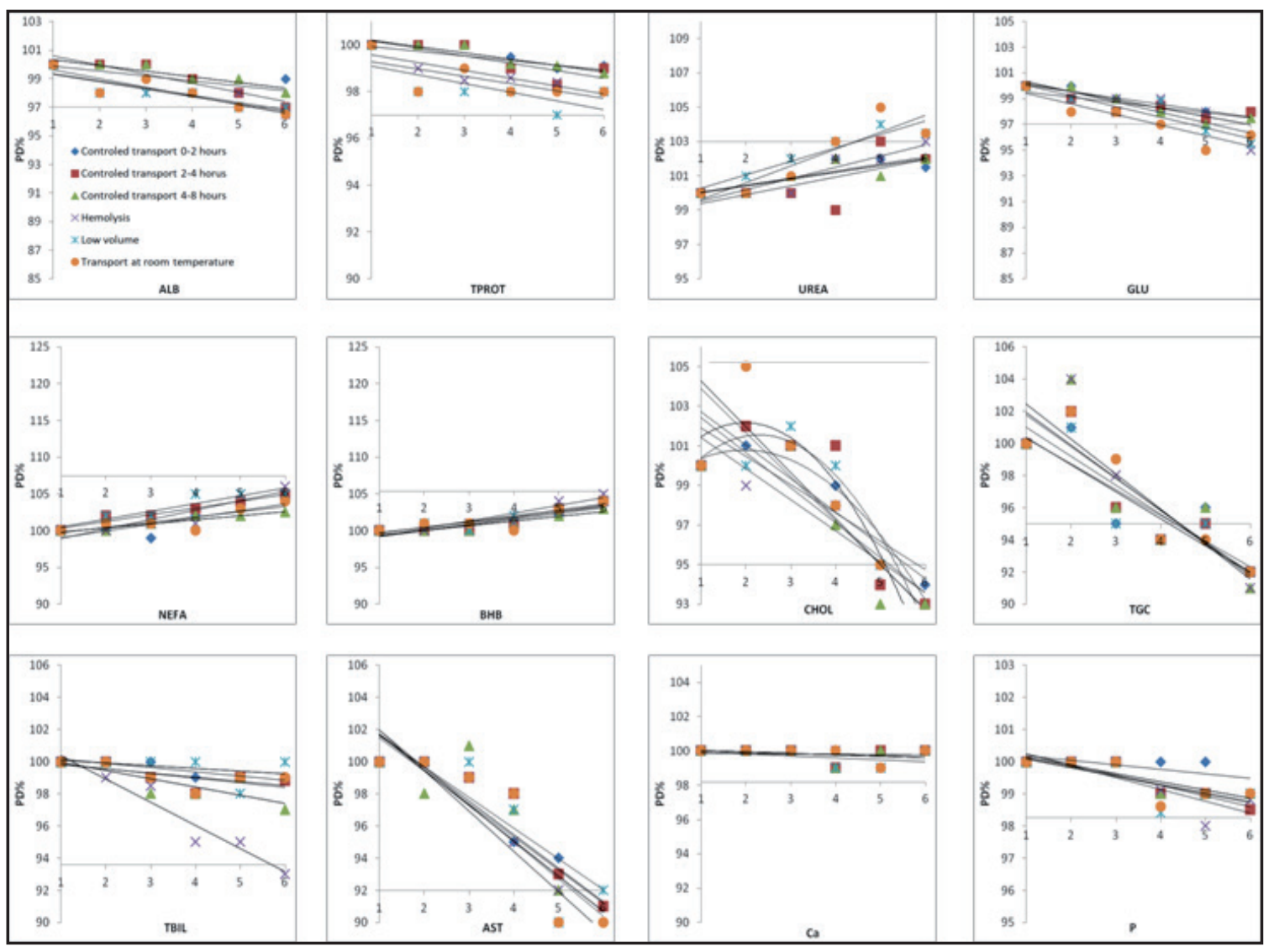

Figure 3. Blood serum analyte stability at $-20^{\circ} \mathrm{C}$ (abscissa represents 1-6 month of measurement). 
D. Kovačević, M. Cincović, B. Belić, R. Đoković \& M. Majkić. 2021. Blood Serum Stability Limit and Maximum Storage Time of Bovine Samples.

Acta Scientiae Veterinariae. 49: 1815.

Table 1. Analyte concentration. change of PD\% during storage time (linear b PD\%) and stability limit (SL) for blood serum metabolic parameters at $+4^{\circ} \mathrm{C}$ and $-20^{\circ} \mathrm{C}$.

\begin{tabular}{|c|c|c|c|c|c|c|c|c|c|}
\hline \multirow{2}{*}{ Parameter } & \multirow{2}{*}{ Value 95CI } & \multirow{2}{*}{ Storage } & \multirow{2}{*}{$\begin{array}{c}\text { Stability } \\
\text { parameter }\end{array}$} & \multicolumn{3}{|c|}{ Optimal transport } & \multicolumn{3}{|c|}{ Preanalytical error } \\
\hline & & & & $0-4 \mathrm{~h}$ & $4-8 \mathrm{~h}$ & $>8 \mathrm{~h}$ & $\mathrm{HL}^{*}$ & UF* $^{*}$ & ATT* \\
\hline \multirow{4}{*}{$\operatorname{ALB}(\mathrm{g} / \mathrm{L})$} & \multirow{4}{*}{$27.2-39.4$} & \multirow{2}{*}{$+4^{\circ} \mathrm{C}$} & Linear b PD\% & -0.22 & -0.23 & -0.5 & -0.77 & -0.72 & -0.65 \\
\hline & & & SL (day) & $>6$ & $>6$ & $>6$ & 4.01 & 4.99 & 4.99 \\
\hline & & \multirow{2}{*}{$-20^{\circ} \mathrm{C}$} & Linear b PD\% & -0.19 & -0.18 & -0.16 & -0.55 & -0.51 & -0.52 \\
\hline & & & SL (month) & $>6$ & $>6$ & $>6$ & 5.51 & 5.53 & 5.54 \\
\hline \multirow{4}{*}{$\begin{array}{c}\text { TPROT } \\
(\mathrm{g} / \mathrm{L})\end{array}$} & \multirow{4}{*}{$67.5-84.7$} & \multirow{2}{*}{$+4^{\circ} \mathrm{C}$} & Linear b PD\% & -0.2 & -0.21 & -0.22 & -0.33 & -0.45 & -0.36 \\
\hline & & & SL (day) & $>6$ & $>6$ & $>6$ & $>6$ & 5.98 & $>6$ \\
\hline & & \multirow{2}{*}{$-20^{\circ} \mathrm{C}$} & Linear b PD\% & -0.21 & -0.20 & -0.24 & -0.3 & -0.32 & -0.39 \\
\hline & & & SL (month) & $>6$ & $>6$ & $>6$ & $>6$ & $>6$ & $>6$ \\
\hline \multirow{4}{*}{$\begin{array}{c}\text { UREA } \\
(\mathrm{mmol} / \mathrm{L})\end{array}$} & \multirow{4}{*}{ 2.13-9.48 } & \multirow{2}{*}{$+4^{\circ} \mathrm{C}$} & Linear b PD\% & 0.50 & 0.52 & 0.76 & 0.95 & 1.21 & 1.25 \\
\hline & & & SL (day) & $>6$ & $>6$ & 3.94 & 3.19 & 2.48 & $2.4 \mathrm{~h}$ \\
\hline & & \multirow{2}{*}{$-20^{\circ} \mathrm{C}$} & Linear b PD\% & 0.38 & 0.36 & 0.37 & 0.37 & 0.78 & 0.79 \\
\hline & & & SL (month) & $>6$ & $>6$ & $>6$ & $>6$ & 4.84 & 4.84 \\
\hline \multirow{4}{*}{$\begin{array}{c}\text { GLU } \\
(\mathrm{mmol} / \mathrm{L})\end{array}$} & & & Linear b PD\% & -0.71 & -1.08 & -7.8 & -1.3 & -1.35 & -1.44 \\
\hline & 185348 & $+4^{\circ} \mathrm{C}$ & SL (day) & 5.65 & $4.5 \mathrm{~h}$ & 4.52 & 3.51 & 3.02 & 2.5 \\
\hline & $1.85-3.48$ & $20 \circ \mathrm{C}$ & Linear b PD\% & -0.74 & -0.75 & -0.8 & -0.82 & -0.83 & -0.83 \\
\hline & & $-20 \mathrm{C}$ & SL (month) & $>6$ & 5.9 & 5.9 & 4.5 & 5.2 & 4 \\
\hline & & $10^{\circ} \mathrm{C}$ & Linear b PD\% & 1.08 & 2.25 & 2.33 & 4.21 & 4.44 & 5.02 \\
\hline NEFA & & $+4^{\circ} \mathrm{C}$ & SL (day) & $>6$ & 4.21 & 3.95 & 3 & 2.6 & 2.3 \\
\hline$(\mathrm{mmol} / \mathrm{L})$ & $0.35-1.17$ & & Linear b PD\% & 0.91 & 0.93 & 0.95 & 0.9 & 0.92 & 0.95 \\
\hline & & $-20^{\circ} \mathrm{C}$ & SL (month) & $>6$ & $>6$ & $>6$ & $>6$ & $>6$ & $>6$ \\
\hline & & $4^{\circ} \mathrm{C}$ & Linear b PD\% & 0.68 & 0.68 & 0.69 & 0.7 & 0.7 & 0.69 \\
\hline BHB & 025133 & $+4^{\circ} \mathrm{C}$ & SL (day) & $>6$ & $>6$ & $>6$ & $>6$ & $>6$ & $>6$ \\
\hline$(\mathrm{mmol} / \mathrm{L})$ & $0.25-1.33$ & $-20^{\circ} \mathrm{C}$ & Linear b PD\% & 0.69 & 0.7 & 0.71 & 0.73 & 0.7 & 0.98 \\
\hline & & $-20^{\circ} \mathrm{C}$ & SL (month) & $>6$ & $>6$ & $>6$ & $>6$ & $>6$ & $>6$ \\
\hline & & $+4^{\circ} \mathrm{C}$ & Linear b PD\% & -0.56 & -0.6 & 0.35 & 0.48 & -0.61 & -0.57 \\
\hline CHOL & 185.607 & +4 C & SL (day) & $>6$ & $>6$ & $>6$ & $>6$ & $>6$ & $>6$ \\
\hline$(\mathrm{mmol} / \mathrm{L})$ & $1.05-0.92$ & $20^{\circ} \mathrm{C}$ & Linear b PD\% & -1.51 & -1.52 & -1.49 & -1.56 & -1.5 & -1.47 \\
\hline & & $-20^{\circ} \mathrm{C}$ & SL (month) & 5.9 & 5.3 & 5.6 & 5.1 & 5.5 & 5.8 \\
\hline & & $+4^{\circ} \mathrm{C}$ & Linear b PD\% & 0.04 & -0.21 & 0.25 & 0.3 & -0.3 & 0.27 \\
\hline TGC & 007038 & $+4^{\circ} \mathrm{C}$ & SL (day) & $>6$ & $>6$ & $>6$ & $>6$ & $>6$ & $>6$ \\
\hline$(\mathrm{mmol} / \mathrm{L})$ & $0.01-0.38$ & & Linear b PD\% & -1.65 & -1.6 & -1.8 & -1.92 & -1.68 & -1.7 \\
\hline & & $-20^{\circ} \mathrm{C}$ & SL (month) & 4.6 & 4.3 & 4.4 & 4.2 & 4.2 & 4.5 \\
\hline & & & Linear b PD\% & -0.37 & -0.65 & -0.46 & -0.93 & -0.75 & -0.61 \\
\hline TBIL & & $+4^{\circ} \mathrm{C}$ & SL (day) & $>6$ & $>6$ & $>6$ & $>6$ & $>6$ & $>6$ \\
\hline$(\mu \mathrm{mol} / \mathrm{L})$ & $2.14-16.05$ & $20^{\circ} \mathrm{C}$ & Linear b PD\% & -0.25 & -0.17 & -0.23 & -1.42 & -0.19 & -0.26 \\
\hline & & $-20^{\circ} \mathrm{C}$ & SL (month) & $>6$ & $>6$ & $>6$ & 5.7 & $>6$ & $>6$ \\
\hline & & $+4^{\circ} \mathrm{C}$ & Linear b PD\% & -0.49 & -0.45 & -0.5 & -0.52 & -0.41 & -0.43 \\
\hline AST & $745-1292$ & $+4^{\circ} \mathrm{C}$ & SL (day) & $>6$ & $>6$ & $>6$ & $>6$ & $>6$ & $>6$ \\
\hline (IU/L) & $74.5-129.2$ & $20^{\circ} \mathrm{C}$ & Linear b PD\% & -2.19 & -2.15 & -2.22 & -2.51 & -2.24 & -2.17 \\
\hline & & $-20^{\circ} \mathrm{C}$ & SL (month) & 5.15 & 5.17 & 5.2 & 5 & 5.68 & 5.7 \\
\hline & & $+4{ }^{\circ} \mathrm{C}$ & Linear b PD\% & -0.21 & -0.22 & 0.18 & -0.21 & -0.2 & -0.18 \\
\hline $\mathrm{Ca}$ & $189-267$ & $+4 \mathrm{C}$ & SL (day) & $>6$ & $>6$ & $>6$ & $>6$ & $>6$ & $>6$ \\
\hline$(\mathrm{mmol} / \mathrm{L})$ & $1.09-2.07$ & $-20^{\circ} \mathrm{C}$ & Linear b PD\% & -0.08 & -0.09 & 0.07 & -0.07 & -0.08 & -0.09 \\
\hline & & $-20 \mathrm{C}$ & SL (month) & $>6$ & $>6$ & $>6$ & $>6$ & $>6$ & $>6$ \\
\hline & & & Linear b PD\% & -0.46 & -0.4 & -0.5 & -0.63 & -0.66 & -0.83 \\
\hline $\mathrm{P}$ & & $+4^{\circ} \mathrm{C}$ & SL (day) & 5.05 & 4.9 & 2.85 & 2.3 & 4.45 & 2.85 \\
\hline$(\mathrm{mmol} / \mathrm{L})$ & $1.68-2.56$ & $20^{\circ} \mathrm{C}$ & Linear b PD\% & -0.14 & -0.15 & -0.2 & -0.19 & -0.22 & -0.27 \\
\hline & & $-20 \mathrm{C}$ & SL (month) & $>6$ & $>6$ & $>6$ & $>6$ & $>6$ & $>6$ \\
\hline
\end{tabular}

*HL: hemolysed sample; UF: underfilled sample; ATT: ambiental (room) temperature transportation. 


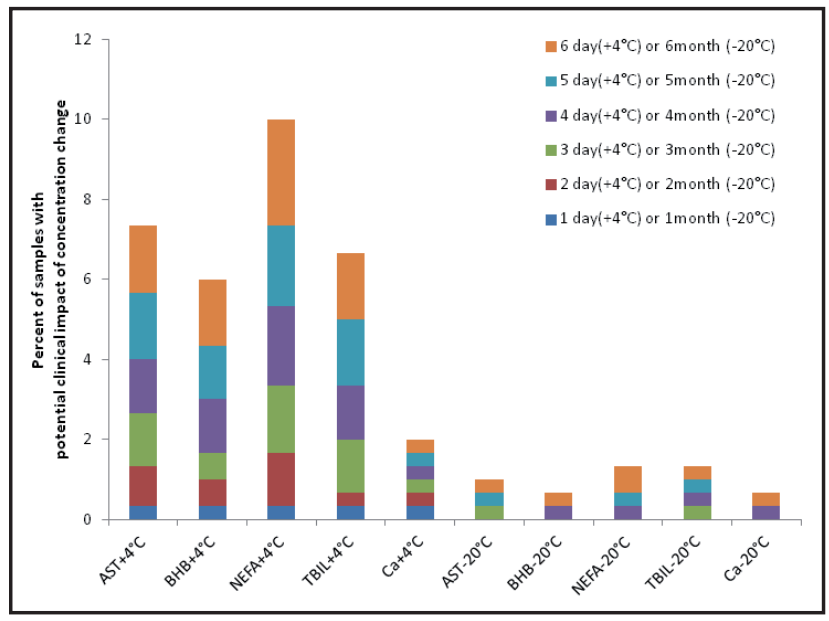

Figure 4. Percent of sample with potential clinicaly impact of analyte concentration change during stability test.

\section{DISCUSSION}

Metabolic profile involves determining a number of different parameters that indicate energy balance (NEFA, BHB, glucose), protein balance (total proteins, albumins, urea), liver functional status (AST, ALT, GGT, total bilirubin, triglycerides and cholesterol) and mineral status $(\mathrm{Ca}, \mathrm{P}$ and $\mathrm{Mg})[2,33]$. The concentration of metabolic parameters in cows is within the values established so far for this animal species [3,9]. Within each of the six test groups, the concentrations of test parameters were uniform. Uniformity of initial concentrations is of great importance, because it is known that percent changes depend on baseline levels in some analytes [8].

The selection of pre-analytical factors was made on the basis of their importance in everyday practice. Preanalytical factors can greatly affect the values and stability of analytes in the blood. Prolonged contact of serum with cellular components and coagulum reduces the stability of the analyte, but serum is considered a more stable sample compared to plasma [6]. The use of different vacutainers and anticoagulants can lead to a significant deviation in the value of plasma metabolites in dairy cows in relation to serum [4]. Long-term storage of the sample at $-20^{\circ} \mathrm{C}$ gives acceptable results for 90 days, while prolonged stability of the analyte is achieved when stored at $-70^{\circ} \mathrm{C}[10]$. Studies show that preanalytical and postanalytical factors (i.e. sample transportation time and retained sample storage temperature) can have a significant impact on parameter variability in the analytical phase [34]. Hemolysis reduces the stability of vitamins, hormones, and drugs in the blood [5, 17], and our study has shown that a large number of analytes are less stable in hemolyzed samples. Under-filling of the sample leads to the development of hemolysis and changes in metabolic values [29]. Insufficient filling occurs as a consequence of poor venipuncture, weak vacuum in the tube, or as a consequence of opening the vacuum tube, which often leads to mixing with air, when foam develops in the sample, mechanical damage to the sample, hemolysis and effects on analytes [28]. In addition to hemolysis in such samples, there may be a problem with altered turbidimetry, probably due to incomplete clot formation and the existence of latent fibrin formation [24]. Leaving the sample at ambient temperature, after which it is deposited at $+4^{\circ} \mathrm{C}$, leads to a significant variation of the analyte in relation to the procedure in which the samples are immediately placed at $+4^{\circ} \mathrm{C}$ [22], with which our results agree.

There are different indices used to determine sample stability. The most commonly used are critical change value (CCV), the maximum permissible instability (MPI) and the total allowable error (TEa). MPI is a much stricter criterion, because it leads to the rejection of a larger number of analytes at a certain time point in relation to $\mathrm{CCV}$, which makes a significantly larger number of analytes acceptable [40]. MPI largely depends on the variability of blood parameters and is directly calculated based on the data of the author Kovačević et al. [23], who come from the same research group and laboratory in which this research was conducted. The greater the analytical and intraindividual variability of blood parameters, the higher the MPI value will be. Based on the obtained MPI value, we conclude that ALB, TPROT, UREA, GLU, Ca and P are more stable parameters compared to NEFA, BHB, CHOL, TGC, AST and TBIL. The obtained results are mainly in accordance with the categorization given by Van Saun [41] relative to parameters variability and diagnostic value.

The dynamics and magnitude of changes in metabolite values largely correspond to previous studies that examined the stability of samples in different populations of animals and humans [8,13,14,19,20,26,30,35,38,39]. Shimizu and Ichihara [36] examined the stability of samples at six temperature regimes and showed that each analyte has a specific pattern of stability at different temperatures, but the dynamics of changes in analyte values over time are similar in different temperature regimes, 
with which our results agree. The concentration of NEFA at $+4^{\circ} \mathrm{C}$ was preserved only during rapid transport of the sample to the laboratory, while prolonged transport and the presence of preanalytical factors significantly reduced the stability of NEFA to 1-3 days (24-48 h). NEFA was stable at $-20^{\circ} \mathrm{C}$ throughout the study period. Our results agree with Stokol and Naydan [37] who showed that NEFA concentrations were stable at $+4^{\circ} \mathrm{C}$ for $72 \mathrm{~h}$ in separated plasma or serum and significantly higher stability at $-20^{\circ} \mathrm{C}$. The temperature regime at $-20^{\circ} \mathrm{C}$ is the only acceptable regime for long term storage of samples for the determination of NEFA, whose stability will not change during 14 days [25]. BHB showed stability in all test conditions and all time points, which also agrees with the previously cited authors. An increase in NEFA concentration over time at $+4^{\circ} \mathrm{C}$ was found in both sheep and humans [26,27]. Ca concentration was stable regardless of the action of preanalytical factors, storage mode and time-point. Similar results were obtained by Bach et al. [1]. Due to the degradation of the samples, the concentration of the analyte decreases over time. Potential clinical significance was determined in a certain percentage of samples for TBIL, AST, NEFA, $\mathrm{BHB}$ and $\mathrm{Ca}$. Potential clinical impact was confirmed for TBIL in a previous stability test [15]. Limit values of these parameters have been determined, which with high specificity and sensitivity indicate various diseases or poor metabolic adaptation [3,7,11], so it is necessary to consider whether deviations of analyte values during the stability test can lead to misinterpretation a certain point in time.

\section{CONCLUSIONS}

The largest number of biochemical analytes in bovine blood serum shows preserved stability in the first 6 days at $+4^{\circ} \mathrm{C}$ or 6 months at $-20^{\circ} \mathrm{C}$ if transported to the laboratory within $8 \mathrm{~h}$ after sampling in ideal conditions and without the action of preanalytical errors. Prolonged transport under ideal conditions or the existence of preanalytical factors such as inadequate transport at room temperature, hemolysis or small sample volume shorten the stability of the samples in both temperature regimes.

This study can help define acceptable delay times and storage conditions for bovine blood samples, which is of great importance because in working with farm animals it is often not possible to take samples in a short time and deliver them to the laboratory, and samples are often burdened with certain preanalytical errors with limited possibilities of re-sampling.

\author{
MANUFACTURERS \\ ${ }^{1}$ Becton, Dickinson and Company. Newark, NJ, USA. \\ ${ }^{2}$ BioSystems S.A. Barcelona, Spain. \\ ${ }^{3}$ Rayto Life and Analytical Sciences Co. Ltd. Shenzhen, China. \\ ${ }^{4}$ International Business Machines Corporation. Armonk, NY, USA.
}

Funding. This research was supported by grants No. 451-039/2021-14/200117 from Ministry of education, science and technological development Serbia.

Ethical approval. The Ethics Committee on animal use at University of Novi Sad (number IV-2017-02) approved this study.

Declaration of interest. The authors report no conflicts of interest. The authors alone are responsible for the content and writing of the paper.

\section{REFERENCES}

1 Bach K.D., Neves R.C., Stokol T. \& McArt J.A.A. 2020. Effect of storage time and temperature on total calcium concentrations in bovine blood. Journal of Dairy Science. 103(1): 922-928.

2 Belić B., Cincović M., Lakić I., Đoković R., Petrović M., Ježek J. \& Starič J. 2018. Metabolic status of dairy cows grouped by anabolic and catabolic indicators of metabolic stress in early lactation. Acta Scientiae Veterinariae. 46(1): 1607. 9p.

3 Belić B. \& Cincović M.R. 2020. Referentne Vrednosti Kod Goveda. In: Referentne Vrednosti Laboratorijskih Parametara U Krvi Životinja. Novi Sad: Poljoprivredni fakultet - Departman za veterinarsku medicinu, pp.40-78.

4 Belić B., Cincović M.R., Došenović M., Stojanović D. \& Kovačević Z. 2015. The effects of different anticoagulants on biochemical parameters in blood of dairy cows. Veterinarski Glasnik. 69(1-2): 13-20.

5 Bérubé E.R., Taillon M.P., Furtado M. \& Garofolo F. 2011. Impact of sample hemolysis on drug stability in regulated bioanalysis. Bioanalysis. 3(18): 2097-2105.

6 Boyanton B.L. \& Blick K.E. 2002. Stability studies of twenty-four analytes in human plasma and serum. Clinical Chemistry. 48(12): 2242-2247.

7 Cincović M.R., Belić B., Radojičić B., Hristov S. \& Đoković R. 2012. Influence of lipolysis and ketogenesis to metabolic and hematological parameters in dairy cows during periparturient period. Acta Veterinaria. 62(4): 429-444. 
8 Clark S., Youngman L.D., Palmer A., Parish S., Peto R. \& Collins R. 2003. Stability of plasma analytes after delayed separation of whole blood: implications for epidemiological studies. International Journal of Epidemiology. 32(1): 125-130.

9 Cozzi G., Ravarotto L., Gottardo F., Stefani A.L., Contiero B., Moro L., Brscic M. \& Dalvit P. 2011. Reference values for blood parameters in Holstein dairy cows: Effects of parity, stage of lactation, and season of production. Journal of Dairy Science. 94(8): 3895-3901.

10 Cray C., Rodriguez M., Zaias J. \& Altman N.H. 2009. Effects of storage temperature and time on clinical biochemical parameters from rat serum. Journal of the American Association for Laboratory Animal Science. 48(2): 202-204.

11 Delić B., Belić B., Cincović M.R., Djokovic R. \& Lakić I. 2020. Metabolic adaptation in first week after calving and early prediction of ketosis type I and II in dairy cows. Large Animal Review. 26(2): 51-55.

12 Djoković R., Kurćubić V., Ilić Z., Cincović M., Lalović M., Jašović B. \& Bojkovski J. 2017. Correlation between blood biochemical metabolites milk yield, dry matter intake and energy balance in dairy cows during early and mid lactation. Advances in Diabetes and Metabolism. 5(2): 26-30.

13 Donnelly J.G., Soldin S.J., Nealon D.A. \& Hicks J.M. 1995. Stability of twenty-five analytes in human serum at 22 degrees C, 4 degrees C, and -20 degrees C. Pediatric Pathology \& Laboratory Medicine. 15(6): 869-874.

14 Ehsani A., Afshari A., Bahadori H., Mohri M. \& Seifi H.A. 2008. Serum constituents analyses in dairy cows: Effects of duration and temperature of the storage of clotted blood. Research in Veterinary Science. 85(3): 473-475.

15 Flores C.F.Y., Pineda Á.D.L.M.H., Bonilla V.M.C. \& Sáenz-Flor K. 2020. Sample management: stability of plasma and serum on different storage conditions. Electronic Journal of the International Federation of Clinical Chemistry and Laboratory Medicine. 31(1): 46-55.

16 Gómez-Rioja R., Amaro M.S., Diaz-Garzón J., Bauçà J.M., Espartosa D.M. \& Fernández-Calle P. 2019. A protocol for testing the stability of biochemical analytes. Technical document. Clinical Chemistry and Laboratory Medicine. 57(12): 1829-1836.

17 Hooser S.B., McCarthy J.M., Wilson C.R., Harms J.L., Stevenson G. \& Everson R.J. 2000. Effects of storage conditions and hemolysis on vitamin E concentrations in porcine serum and liver. Journal of Veterinary Diagnostic Investigation. 12(4): 365-368.

18 Humann-Ziehank E. \& Ganter M. 2012. Pre-analytical factors affecting the results of laboratory blood analyses in farm animal veterinary diagnostics. Animal. 6(7): 1115-1123.

19 Jones D.G. 1985. Stability and storage characteristics of enzymes in cattle blood. Research in Veterinary Science. 38(3): 301-306.

20 Jones D.G. 1985. Stability and storage characteristics of enzymes in sheep blood. Research in Veterinary Science. 38(3): 307-311.

21 Kida K. 2002. The metabolic profile test: its practicability in assessing feeding management and periparturient diseases in high yielding commercial dairy herds. Journal of Veterinary Medical Science. 64(7): 557-563.

22 Kift R.L., Byrne C., Liversidge R., Babbington F., Knox C., Binns J. \& Barth J.H. 2015. The effect of storage conditions on sample stability in the routine clinical laboratory. Annals of Clinical Biochemistry. 52(6): 675-679.

23 Kovačević V., Cincović M.R., Belić B., Đoković R., Lakić I., Radinović M., Potkonjak A. 2021. Biological variations of hematologic and biochemical parameters in cows during early lactation. Polish Journal of Veterinary Science. 24(1): 119-125.

24 Magee L.S. 2005. Preanalytical variables in the chemistry laboratory. In: Lab Notes. Franklin Lakes: Becton, Dickinson and Company, pp.1-6.

25 Menéndez L.G., Fernández A.L., Enguix A., Ciriza C. \& Amador J. 2001. Effect of storage of plasma and serum on enzymatic determination of non-esterified fatty acids. Annals of Clinical Biochemistry. 38(3): 252-255.

26 Moe M.O., Okstad W., Berland S. \& Framstad T. 2018. Effects of storage duration and temperature conditions on biochemical analytes in porcine clotted, uncentrifuged blood samples. Journal of Dairy, Veterinary and Animal Research. 7(1): 00181.

27 Morris J.D., Fernandez J.M., Chapa A.M., Gentry L.R., Thorn K.E., \& Weick T.M. 2002. Effects of sample handling, processing, storage and hemolysis on measurements of key energy metabolites in ovine blood. Small Ruminant Research. 43:157-166.

28 Mullins G.R. \& Bruns D.E. 2017. Air bubbles and hemolysis of blood samples during transport by pneumatic tube systems. Clinica Chimica Acta. 473: 9-13. 
29 Neuwinger N., Zum D.M.B., Tauber R. \& Kappert K. 2020. Underfilling of vacuum blood collection tubes leads to increased lactate dehydrogenase activity in serum and heparin plasma samples. Clinical Chemistry and Laboratory Medicine. 58(2): 213-221.

30 Oddoze C., Lombard E. \& Portugal H. 2012. Stability study of 81 analytes in human whole blood, in serum and in plasma. Clinical Biochemistry. 45(6): 464-469.

31 Overton T.R., McArt J.A.A. \& Nydam D.V. 2017. A 100-Year Review: Metabolic health indicators and management of dairy cattle. Journal of Dairy Science. 100(12): 10398-10417.

32 Payne J. M., Dew S.M., Manston R. \& Faulks M. 1970. The use of a metabolic profile test in dairy herds. Veterinary Record. 87(6): 150-158.

33 Puppel K., Kuczyńska B. 2016. Metabolic profiles of cow's blood; a review. Journal of the Science of Food and Agriculture. 96(13): 4321-4328.

34 Rasalkar K. \& Suma H.R. 2017. The impact of preanalytical variable like delay in sample transportation and post analytical variable like deep freezer temperature on combined Measurement Uncertainty. International Journal of Medical Science and Clinical Inventions. 4(6): 3034-3036.

35 Rioja R.G., Espartosa D.M., Segovia M., Ibarz M., Llopis M.A., Bauça J.M., Marzana I., Barba N., Ventura M., del Pino I.G., Puente J.J., Caballero A., Gómez C., Álvarez A.G., Alsina M.J. \& Álvarez V. 2018. Laboratory sample stability. Is it possible to define a consensus stability function? An example of five blood magnitudes. Clinical Chemistry and Laboratory Medicine. 56(11): 1806-1818.

36 Shimizu Y. \& Ichihara K. 2019. Elucidation of stability profiles of common chemistry analytes in serum stored at six graded temperatures. Clinical Chemistry and Laboratory Medicine. 57(9): 1388-1396.

37 Stokol T. \& Nydam D.V. 2005. Effect of anticoagulant and storage conditions on bovine nonesterified fatty acid and $\beta$-hydroxybutyrate concentrations in blood. Journal of Dairy Science. 88(9): 3139-3144.

38 Tanner M., Kent N., Smith B., Fletcher S. \& Lewer M. 2008. Stability of common biochemical analytes in serum gel tubes subjected to various storage temperatures and times pre-centrifugation. Annals of Clinical Biochemistry. 45(4): 375-379.

39 Taylor E.C. \& Sethi B. 2011. Stability of 27 biochemistry analytes in storage at a range of temperatures after centrifugation. British Journal of Biomedical Science. 68(3): 147-157.

40 Van Balveren J.A., Huijskens M.J., Gemen E.F., Péquériaux N.C. \& Kusters R. 2017. Effects of time and temperature on 48 routine chemistry, haematology and coagulation analytes in whole blood samples. Annals of Clinical Biochemistry. 54(4): 448-462.

41 Van Saun R. 2000. Blood profiles as indicators of nutritional status. In: 18th Annual Western Canadian Dairy Seminar (Red Deer Alberta, Canada). pp.1-6. 